\title{
Role of Rho-kinase in mediating contraction of chicken embryo femoral arteries
}

\author{
Bea Zoer • Carlos E. Blanco • Eduardo Villamor
}

Received: 2 July 2009 / Revised: 9 September 2009 / Accepted: 3 November 2009 / Published online: 20 November 2009

(C) The Author(s) 2009. This article is published with open access at Springerlink.com

\begin{abstract}
Rho-kinase-dependent $\mathrm{Ca}^{2+}$ sensitization is an essential process for contraction of mammalian vascular smooth muscle but the information about its effects in nonmammalian vessels is scarce. We aimed to investigate, using the Rho-kinase inhibitor hydroxyfasudil, the potential role of the Rho-kinase pathway of $\mathrm{Ca}^{2+}$ sensitization in depolarization- and agonist-mediated contraction of chicken embryo (at day 19 of the 21 days of incubation) femoral arteries. Contraction elicited by $\mathrm{KCl}(125 \mathrm{mM})$ comprised two phases (phasic and tonic contraction), both of which were abolished in the absence of extracellular $\mathrm{Ca}^{2+}$. Hydroxyfasudil (10 $\left.\mu \mathrm{M}\right)$ left the initial phasic component nearly intact but abolished the tonic component. Hydroxyfasudil also induced a marked impairment of the contractions elicited by phenylephrine (PE), the thromboxane $\mathrm{A}_{2}$ mimetic U46619, and endothelin-1. In contrast, inhibition of protein kinase $\mathrm{C}$ (PKC) by chelerythrine did not affect $\mathrm{KCl}$ - or $\mathrm{PE}$-induced contractions, indicating lack of participation of PKC-mediated $\mathrm{Ca}^{2+}$ sensitization. Incubation under chronic hypoxia $\left(\begin{array}{llll}15 \% & \mathrm{O}_{2} & \text { from day } & 0\end{array}\right)$ impaired embryonic growth but did not significantly affect hydroxyfasudil-mediated relaxation. In summary, our findings are indicative of a role for Rho-kinase activity in depolarization- and agonist-induced force generation in chicken embryo femoral arteries.
\end{abstract}

Communicated by H. V. Carey.

B. Zoer · C. E. Blanco $\cdot$ E. Villamor $(\square)$

Department of Pediatrics,

Maastricht University Medical Centre (MUMC+),

School for Oncology and Developmental Biology (GROW),

P. Debyelaan 25, P.O. Box 5800,

6202 AZ Maastricht, The Netherlands

e-mail: E.Villamor@mumc.nl
Keywords Hydroxyfasudil $\cdot$ Rho-kinase $\cdot$ Chicken embryo $\cdot$ Artery $\cdot$ Chronic hypoxia

\section{Introduction}

Rho-associated kinases, the immediate downstream targets of RhoA, are highly conserved and ubiquitously expressed serine-threonine protein kinases that are implicated in a variety of physiological functions associated with changes in the actin cytoskeleton, such as cell adhesion, motility, migration, and contraction. Thereby, Rho-kinases contribute to the control of some of the most fundamental processes of cell biology common to all eukaryotes, including morphogenesis, polarity, cytokinesis, apoptosis, and cell division (Jaffe and Hall 2005; Noma et al. 2006; Riento and Ridley 2003). In addition, Rho-kinases contribute to changes in gene expression that lead to cell-cycle progression or differentiated cell responses (Riento and Ridley 2003).

In smooth muscle cells, phosphorylation of the regulatory myosin light chain (MLC) is required to initiate contraction. Calcium ions play a primary role in this process. Excitatory agonists induce a rise in the intracellular-free $\mathrm{Ca}^{2+}$ concentration through $\mathrm{Ca}^{2+}$ release from intracellular stores (sarcoplasmic reticulum) as well as entry from the extracellular space through $\mathrm{Ca}^{2+}$ channels. This results in the activation of the $\mathrm{Ca}^{2+}$-calmodulin-dependent MLC kinase (MLCK). MLCK phosphorylates the 20-kDa MLC, leading to the initiation of contraction (Cogolludo et al. 2007; Ratz et al. 2005; Somlyo and Somlyo 2003; Webb 2003). In addition, agonists can induce $\mathrm{Ca}^{2+}$ sensitization, a phenomenon in which sustained constriction occurs, independent of ongoing increases in cytosolic $\mathrm{Ca}^{2+}$, due to MLC phosphatase (MLCP) inhibition and the resulting 
persistence of MLC phosphorylation. Rho-kinase was demonstrated to phosphorylate the $110-\mathrm{kDa}$ myosin binding subunit (MYPT1) of MLCP to inhibit its activity. In addition, Rho-kinase, as well as protein kinase $\mathrm{C}$ (PKC), was shown to phosphorylate and activate a MLCP inhibitor phosphoprotein, CPI-17, to induce $\mathrm{Ca}^{2+}$ sensitization (Cogolludo et al. 2007; Ratz et al. 2005; Somlyo and Somlyo 2003; Webb 2003).

Several specific Rho-kinase inhibitors, such as Y-27632, fasudil, and hydroxyfasudil, have been developed in the past few years (Breitenlechner et al. 2003; Davies et al. 2000; Shimokawa and Rashid 2007). Their use has led to the appreciation of the RhoA/Rho-kinase pathway as a key regulator of smooth muscle contraction in numerous mammalian species (Gao et al. 2007; Kitazawa et al. 2003; Mita et al. 2002; Shimokawa et al. 1999; Wardle et al. 2007). Moreover, in animal and clinical studies, Rho-kinase-mediated $\mathrm{Ca}^{2+}$ sensitization has been shown to be substantially involved in the pathogenesis of vasospasm, arteriosclerosis, hypertension, pulmonary hypertension, and ischemia/reperfusion injury (Shimokawa and Rashid 2007).

Despite its relevance in the mammal, the published information about the effects of Rho-kinase inhibition on vascular smooth muscle reactivity in non-mammalian species is scarce. The chicken embryo is a good model for investigating developmental vascular biology (Ruijtenbeek et al. 2002). Receptor-independent and-dependent contraction as well as endothelium-dependent and -independent relaxation are present in the chicken vasculature as early as 15 days of incubation and undergo marked developmental changes (Agren et al. 2008, 2009; Villamor et al. 2002, 2004). In addition, the normal pattern of development of vascular function can be altered by exposure during incubation to insults such as chronic hypoxia, malnutrition, or drugs (Ruijtenbeek et al. 2000, 2003b; Van der Sterren et al. 2009; Zoer et al. 2009). In the present study we aimed to investigate, using the Rho-kinase inhibitor hydroxyfasudil, the potential role of the RhoA/Rho-kinase pathway of $\mathrm{Ca}^{2+}$ sensitization in depolarization- and agonist-mediated contraction of chicken embryo femoral arteries. We also evaluated whether exposure to chronic hypoxia during incubation affected the vascular response to Rho-kinase inhibition.

\section{Methods}

The experiments were in accordance with the Dutch law for animal experimentation. Fertilized eggs from White Leghorn chickens ('t Anker, Ochten, The Netherlands) were incubated at $37.8^{\circ} \mathrm{C}, 45 \%$ humidity and rotated once an hour over an angle of $90^{\circ}$ (Incubator model 25HS, Masalles Comercial, Spain). Control embryos were incubated under normoxic conditions $\left(21 \% \mathrm{O}_{2}, 0.03 \% \mathrm{CO}_{2}\right)$ and a group of eggs was incubated under hypoxic conditions $(15.0 \pm 0.3 \%$ atmospheric $\mathrm{O}_{2}, 0.03 \% \mathrm{CO}_{2}$ ) from day 0. Hypoxia was maintained by providing a constant flow of $\mathrm{N}_{2}$ and compressed air (3,000 and 4,500 $\mathrm{ml} / \mathrm{min}$, respectively) with a flow meter (AGA Gas BV, The Netherlands), as previously described (Zoer et al., 2009). The $\mathrm{O}_{2}$ and $\mathrm{CO}_{2}$ concentrations in the incubator were monitored with a DrDAQ $\mathrm{O}_{2}$ sensor (Pico Technology, UK) and an infrared $\mathrm{CO}_{2}$ analyzer (Beckman Instruments, Inc., Fullerton, CA, USA).

At day 19 of the 21-day incubation period non-internally pipped chicken embryos were decapitated and femoral arteries were isolated and stored in cold Krebs-Ringer bicarbonate (KRB) buffer. Rings of 1.7-2 mm were made and mounted between an isometric force transducer (Kistler Morce DSC 6, Seattle, WA, USA) and a displacement device in a myograph (model 610M, Danish Myotechnology, Aarhus, Denmark) using two stainless steel wires (diameter $40 \mu \mathrm{m}$ ). During mounting and experimentation, the KRB buffer was maintained at $39^{\circ} \mathrm{C}$ and aerated with $95 \% \mathrm{O}_{2}-5 \% \mathrm{CO}_{2}$. Each artery was stretched to its individual optimal lumen diameter, i.e., the diameter at which it developed the strongest contractile response to $62.5 \mathrm{mM}$ $\mathrm{KCl}$, using a diameter-tension protocol as previously described (Villamor et al. 2002, 2004).

Effects of Rho-kinase and PKC inhibition on chicken embryo femoral artery contraction

The effect of the Rho-kinase inhibitor hydroxyfasudil $(10 \mu \mathrm{M})$ on contractile responses was assessed by treating arterial segments for $30 \mathrm{~min}$ before adding $\mathrm{KCl}(125 \mathrm{mM})$, phenylephrine (PE, $10 \mathrm{nM}$ to $0.1 \mathrm{mM}$ ), the PKC activator 12,13 phorboldibutyrate (PDBu, $1 \mathrm{nM}-1 \mu \mathrm{M}$ ), endothelin-1 $(\mathrm{ET}-1,1 \mathrm{nM}-0.3 \mu \mathrm{M})$, or the thromboxane $\mathrm{A}_{2}$ mimetic U46619 $(10 \mathrm{nM}-3 \mu \mathrm{M})$. The effect of the PKC inhibitor chelerythrine $(10 \mu \mathrm{M})$ on contractile responses to $\mathrm{KCl}$ and $\mathrm{PE}$ was assessed in a similar way. The effects of combined hydroxyfasudil $(10 \mu \mathrm{M})$ and chelerythrine $(10 \mu \mathrm{M})$ were also studied. In another group of experiments, responses to $\mathrm{KCl}, \mathrm{PE}$, and PDBu were studied in $0 \mathrm{Ca}^{2+}$ EGTA $(3 \mathrm{mM})$ $\mathrm{KRB}$ buffer. All experiments involving $\mathrm{KCl}$-induced contractions were performed in the presence of the adrenoceptor blockers prazosin $(1 \mu \mathrm{M})$ and propanolol $(0.1 \mu \mathrm{M})$ to antagonize any effects of catecholamines released from nerve terminals.

\section{Relaxation responses to hydroxyfasudil}

Femoral artery rings were contracted with $\mathrm{KCl}(125 \mathrm{mM}$ in the presence of prazosin and propanolol) or PE $(10 \mu \mathrm{M})$ until a stable contraction was achieved. Rings were then treated with increasing concentrations of hydroxyfasudil 
( $1 \mathrm{nM}$ to $10 \mu \mathrm{M}$ ). Some experiments were performed in the presence of the nitric oxide (NO) synthase (NOS) inhibitor $N^{\omega}$-nitro-L-arginine methyl ester (L-NAME, $100 \mu \mathrm{M}$ ), or the soluble guanylate cyclase inhibitor ODQ $(10 \mu \mathrm{M})$.

\section{Drugs and solutions}

Krebs-Ringer bicarbonate contained (in mmol per liter): $\mathrm{NaCl}, 118.5 ; \mathrm{KCl}, 4.75 ; \mathrm{MgSO}_{4} \cdot 7 \mathrm{H}_{2} \mathrm{O}, 1.2 ; \mathrm{KH}_{2} \mathrm{PO}_{4}, 1.2$; $\mathrm{NaHCO}_{3}, 25.0 ; \mathrm{CaCl}_{2}, 2.5$; glucose, 5.5. Solutions containing different concentrations of $\mathrm{K}^{+}$were prepared by replacing part of the $\mathrm{NaCl}$ by an equimolar amount of $\mathrm{KCl}$. U46619 was obtained from Cayman Chemical (Ann Arbor, MI, USA), and ODQ was from Tocris (Ballwin, MO, USA). All the other drugs were obtained from Sigma ( $\mathrm{St}$ Louis, MO, USA). All drugs were dissolved initially in distilled deionized water (except U46619 and ODQ, which were dissolved in DMSO) to prepare adequate stock solutions and further dilutions were made in deionized water.

\section{Data analysis}

Results are shown as mean (SD) of measurements in $n$ animals. For clarity, results in the figures are shown as mean $\pm \mathrm{SE}$. Contractions are expressed in terms of active wall tension $(\mathrm{N} / \mathrm{m})$, calculated as the force divided by twice the length of the arterial segment. Relaxant responses are expressed as the percentage of reduction of the contraction induced by $\mathrm{KCl}$ or $\mathrm{PE}$. The potency (expressed as $\mathrm{pD}_{2}=-\log \mathrm{EC}_{50}$ ) and efficacy (expressed as maximal effect: $E_{\max }$ ) of agonists was determined for each artery by fitting individual concentration-response data to a non-linear sigmoidal regression curve and interpolating (Graphpad Prism version 2.01; GraphPad Software Inc, San Diego, CA, USA). Differences between mean values were assessed by one-way ANOVA followed by Bonferroni post hoc $t$ test. Unpaired $t$ tests were used if only two groups were compared. Differences were considered significant at a $P<0.05$. All analyses were performed using a commercially available statistics package (GraphPad InStat version 3.00, GraphPad Software Inc, San Diego, CA, USA).

\section{Results}

\section{$\mathrm{KCl}$-induced contractions}

The addition of $125 \mathrm{mM} \mathrm{KCl}$ to rings of chicken embryo femoral artery induced a contraction that peaked rapidly and transiently (phasic component) and was followed by a slowly developing contraction (tonic component) that reached a plateau after approximately 10-15 min (Fig. 1a). The forces of the phasic and tonic components of contraction evoked by $125 \mathrm{mM} \mathrm{KCl}$ were $1.25 \mathrm{~N} / \mathrm{m}$ (SD 0.34, $n=22$ ) and $1.83 \mathrm{~N} / \mathrm{m}$ (SD 0.43), respectively.

As shown in Fig. 1b, c, in the absence of extracellular $\mathrm{Ca}^{2+}$ the phasic component of $\mathrm{KCl}$-induced contraction was markedly reduced $(0.23 \mathrm{~N} / \mathrm{m}$ SD $0.178, n=4, P<0.001)$ and the tonic component was completely abolished. The presence of hydroxyfasudil $(10 \mu \mathrm{M})$ did not significantly
Fig. 1 a Typical tracing showing the phasic and tonic components of the contractile response of chicken embryo femoral artery to $\mathrm{KCl}(125 \mathrm{mM})$. b, c Effects (mean + SE) of elimination of extracellular $\mathrm{Ca}^{2+}$ (0 Ca +3 mM EGTA), the Rho-kinase inhibitor hydroxyfasudil $(10 \mu \mathrm{M})$, the PKC inhibitor chelerythrine $(10 \mu \mathrm{M})$, and the combination of hydroxyfasudil and chelerythrine in the phasic (b) and the tonic (c) components of $\mathrm{KCl}$-induced contraction. $* P<0.05$ vs control
A

KCl 125 mM

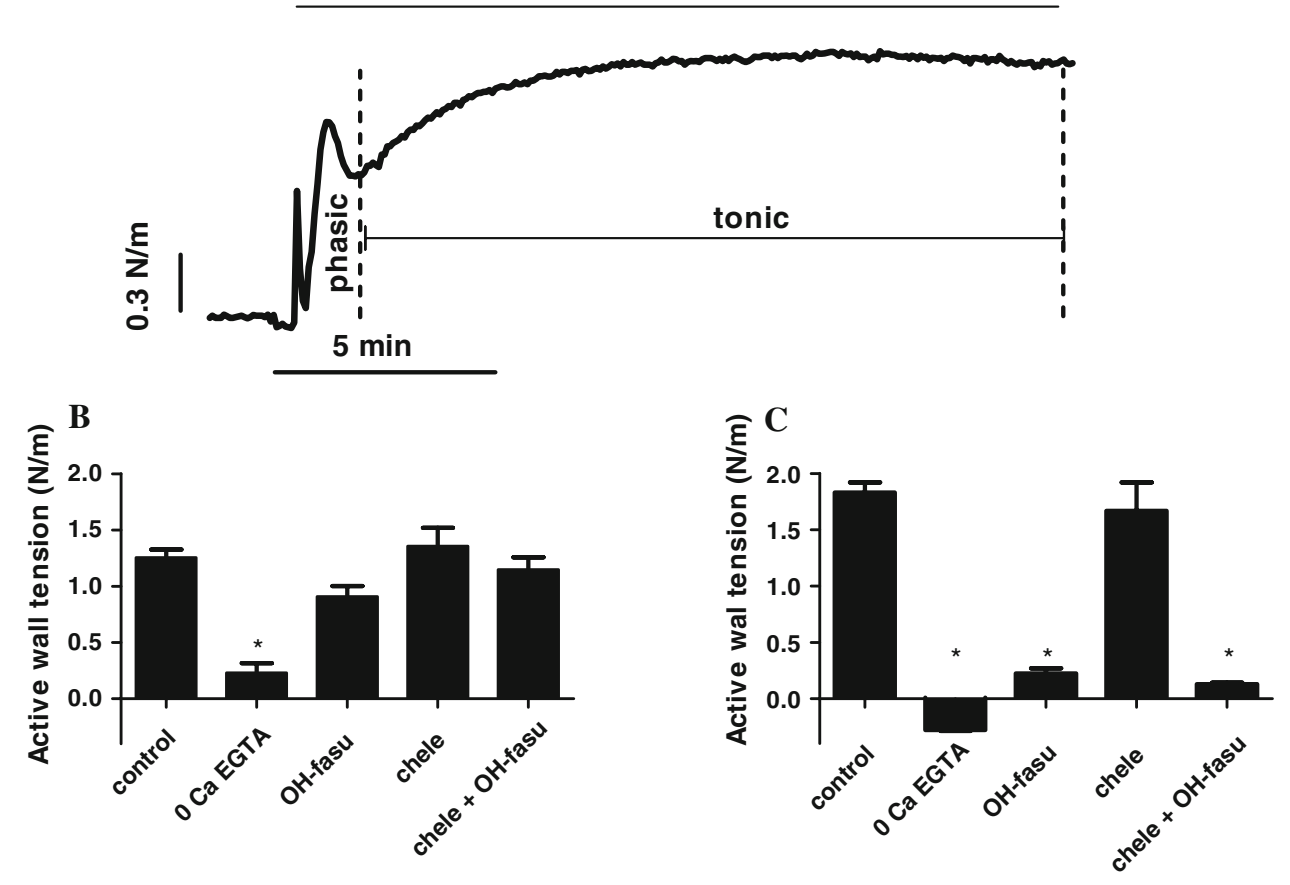


affect KCl-evoked phasic contraction $(0.91 \mathrm{~N} / \mathrm{m}, \mathrm{SD} 0.23$, $n=6)$ but markedly impaired the tonic component $(0.22 \mathrm{~N} / \mathrm{m}$, SD $0.11, P<0.001)$. Chelerythrine $(10 \mu \mathrm{M})$ did not significantly affect either the phasic $(1.36 \mathrm{~N} / \mathrm{m}$, SD 0.49 , $n=9)$ or the tonic $(1.67 \mathrm{~N} / \mathrm{m}, \mathrm{SD} 0.76)$ contraction. The combination of hydroxyfasudil and chelerythrine did not induce a different effect on $\mathrm{KCl}$-evoked contraction (phasic: $1.15 \mathrm{~N} / \mathrm{m}$, SD 0.31 ; tonic: $0.13 \mathrm{~N} / \mathrm{m}$, SD $0.04, n=8$ ) than hydroxyfasudil alone.

PE-, U46619-, and ET-1-induced contractions

The $\alpha_{1}$-adrenegic receptor agonist PE induced concentration-dependent contractions with a mean maximal effect of $2.05 \mathrm{~N} / \mathrm{m}(\mathrm{SD} 0.58, n=15)$ and $\mathrm{a}_{2}$ of $5.90(\mathrm{SD}$ $0.32)$. The absence of $\mathrm{Ca}^{2+}$ significantly reduced the efficacy ( $E_{\max }: 0.41$, SD $0.22, n=6, P<0.001$ vs control) and the potency $\left(\mathrm{pD}_{2}: 4.22, \mathrm{SD} 0.49, P<0.01\right.$ vs control) of $\mathrm{PE}$ to contract the chicken embryo femoral artery (Fig. 2). In the presence of hydroxyfasudil $(10 \mu \mathrm{M})$ the efficacy $\left(E_{\max }: 0.91 \mathrm{~N} / \mathrm{m}, \mathrm{SD} 0.44, n=6, P<0.01\right)$ but not the potency $\left(\mathrm{pD}_{2}: 5.34, \mathrm{SD} 0.27\right)$ of $\mathrm{PE}$ was significantly reduced. In contrast, the PKC-inhibitor chelerythrine did not significantly affect contractions to PE ( $E_{\max }: 2.19 \mathrm{~N} / \mathrm{m}$ SD $0.39 ; \mathrm{pD}_{2}: 5.62, \mathrm{SD} 0.32, n=12$ ). The combination of hydroxyfasudil and chelerythrine did not induce a different effect on PE-evoked contractions $\left(E_{\max }: 0.92 \mathrm{~N} / \mathrm{m} \mathrm{SD}\right.$ $\left.0.32, n=8 ; \mathrm{pD}_{2}: 5.01, \mathrm{SD} 0.24\right)$ than hydroxyfasudil alone.

As shown in Fig. 2b, c, the contractions induced by U46619 and ET-1 were markedly impaired in the presence of hydroxyfasudil $(10 \mu \mathrm{M})$.

\section{PDBu-induced contractions}

As shown in Fig. 3a, the PKC activator PDBu induced a concentration-dependent contraction in the chicken embryo femoral arteries. In contrast, PDBu concentrations $>0.1 \mu \mathrm{M}$ induced relaxation. The mean maximal contraction induced by $\mathrm{PDBu}$ was $1.04 \mathrm{~N} / \mathrm{m}(\mathrm{SD} 0.86, n=18)$ with a $\mathrm{pD}_{2}$ of 7.62 (SD 0.30). In the absence of extracellular $\mathrm{Ca}^{2+}$ these contractions were reduced to $0.25 \mathrm{~N} / \mathrm{m}$, SD $0.10, n=6$ $\left(P<0.04\right.$ vs control) with a $\mathrm{pD}_{2}$ of 7.29, SD $0.07(P<0.02$ vs control). The presence of hydroxyfasudil impaired the potency $\left(\mathrm{pD}_{2}: 7.15 \mathrm{SD} 0.39, n=9, P<0.02\right.$ vs control) but not the efficacy $\left(E_{\max }: 0.52 \mathrm{~N} / \mathrm{m}, \mathrm{SD} 0.47\right)$ of PDBu to contract chicken embryo femoral arteries.

Hydroxyfasudil-induced relaxation

In chicken embryo femoral arteries contracted with $\mathrm{KCl}$ (125 mM, active wall tension: $1.82 \mathrm{~N} / \mathrm{m}$, SD $0.34, n=23$ )
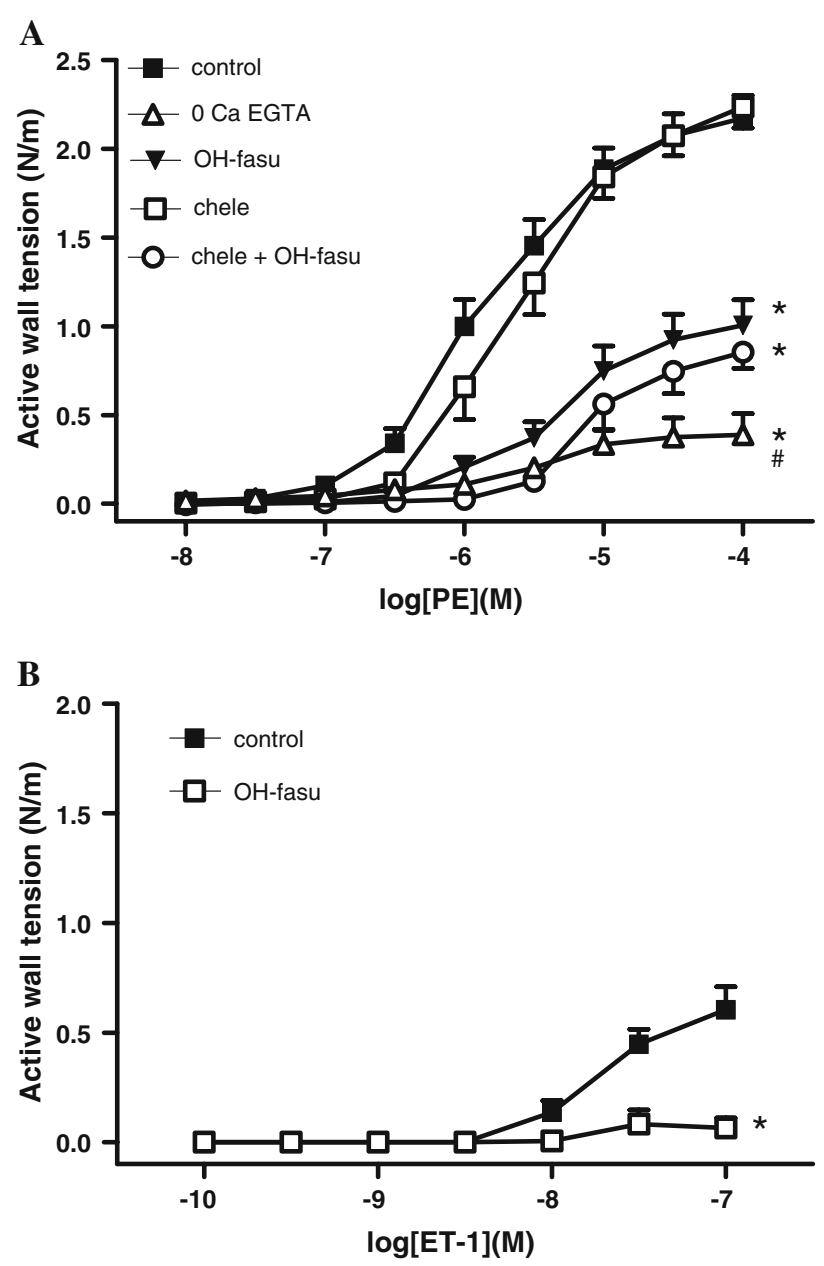

C

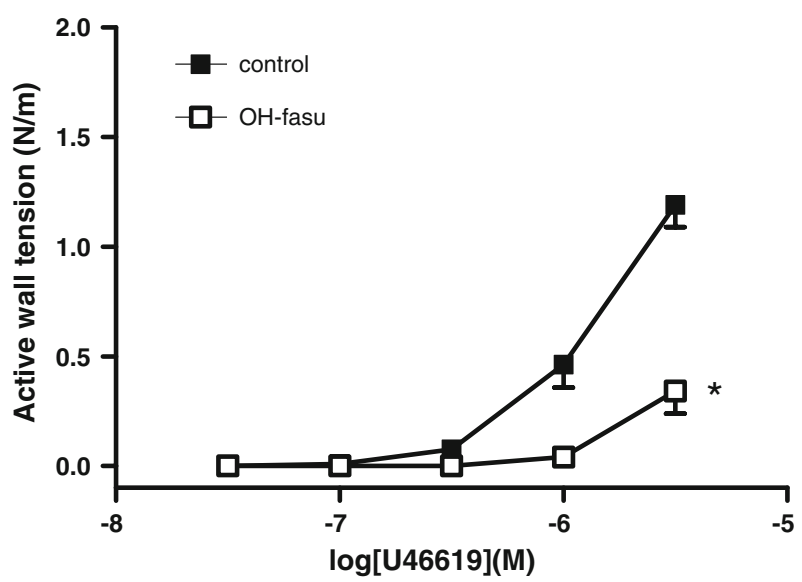

Fig. 2 a Effects (mean $+\mathrm{SE}$ ) of elimination of extracellular $\mathrm{Ca}^{2+}$ (0 $\mathrm{Ca}+3 \mathrm{mM}$ EGTA), the Rho-kinase inhibitor hydroxyfasudil $(10 \mu \mathrm{M})$, the PKC inhibitor chelerythrine $(10 \mu \mathrm{M})$, and the combination of hydroxyfasudil and chelerythrine on the concentration-dependent contraction induced by phenylephrine in chicken embryo femoral arteries. b, c Effects of hydroxyfasudil $(10 \mu \mathrm{M})$ on the contractions induced by endothelin-1 (b) and the thromboxane $\mathrm{A}_{2}$ mimetic U46619 (c). ${ }^{*} P<0.05$ for difference in $E_{\max }$ from control. ${ }^{\#} P<0.05$ for difference in $\mathrm{pD}_{2}$ from control 

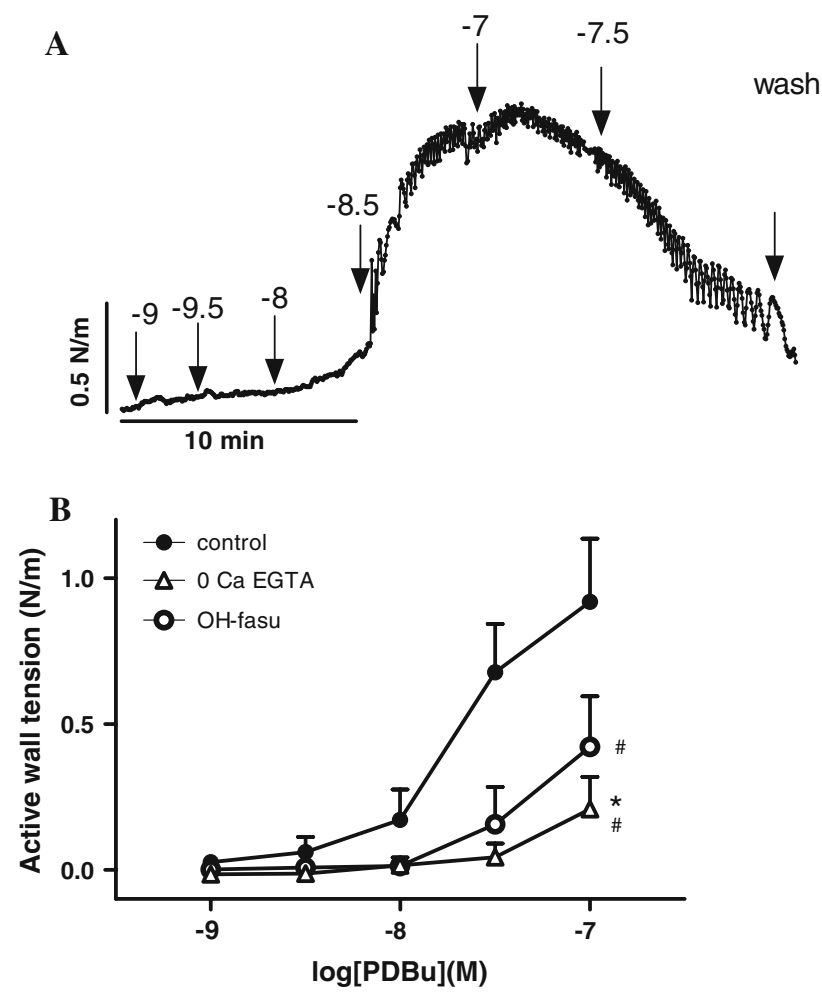

Fig. 3 a Typical tracing showing the effects of cumulative concentrations of the PKC activator 12,13 phorboldibutyrate (PDBu) in the chicken embryo femoral artery. b Effects (mean $+\mathrm{SE}$ ) of elimination of extracellular $\mathrm{Ca}^{2+}(0 \mathrm{Ca}+3 \mathrm{mM}$ EGTA), and the Rho-kinase inhibitor hydroxyfasudil $(10 \mu \mathrm{M})$ on $\mathrm{PDBu}$-induced contractions. ${ }^{*} P<0.05$ for difference in $E_{\max }$ from control. ${ }^{\#} P<0.05$ for difference in $\mathrm{pD}_{2}$ from control

or PE $(10 \mu \mathrm{M}$, active wall tension: $2.18 \mathrm{~N} / \mathrm{m}$, SD 0.59 , $n=12$ ), hydroxyfasudil induced concentration-dependent relaxations (KCl: 97.18\%, SD 5.57; PE: 96.07\%, SD 6.66) with pD2 values of, respectively, 5.96 (SD 0.28) and 5.75 (SD 0.30) that were not significantly different (Fig. 4a). Hydroxyfasudil-induced relaxation of $\mathrm{KCl}$-contracted arteries was significantly impaired by the presence of the NOS inhibitor L-NAME $\left(E_{\max }: 88.51 \%\right.$, SD 5.73; pD2: 5.70, SD $0.08, n=8, P<0.05$ vs control) but not by the presence of the soluble guanylate cyclase inhibitor ODQ $\left(E_{\max }: 94.28 \%, \mathrm{SD} 4.92 ; \mathrm{pD}_{2}: 5.88, \mathrm{SD} 0.25, n=5\right)$ (Fig. 4a).

\section{Effects of chronic hypoxia}

Incubation under chronic hypoxia reduced embryonic body mass $(23.7 \mathrm{~g}$, SD $0.6, n=49$ vs $28.3 \mathrm{~g}$, SD $0.4, n=20$, $P<0.001)$ but did not significantly affect the contraction induced by $\mathrm{KCl}(2.08 \mathrm{~N} / \mathrm{m}, \mathrm{SD} 0.69, n=17)$ or $\mathrm{PE}(2.35 \mathrm{~N} / \mathrm{m}$, SD 1.02, $n=13$ ) in chicken embryo femoral arteries. As shown in Fig. 4b, c, chronic hypoxia did not significantly
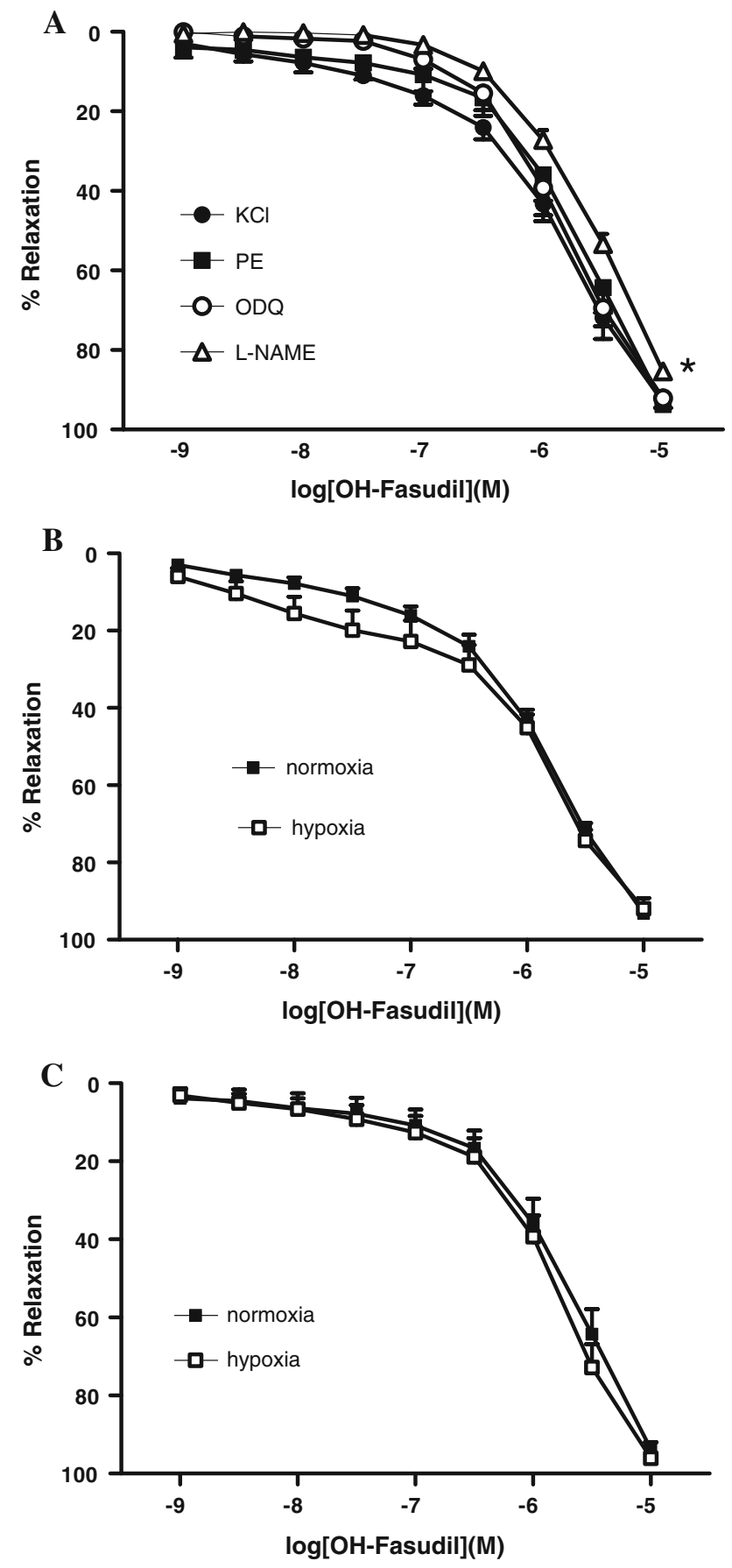

Fig. 4 a Concentration-dependent relaxant effects of hydroxyfasudil in chicken embryo femoral arteries contracted with $\mathrm{KCl}(125 \mathrm{mM})$ or PE $(10 \mu \mathrm{M})$. The effects of the NOS inhibitor L-NAME $(100 \mu \mathrm{M})$ and the sGC inhibitor ODQ $(10 \mu \mathrm{M})$ are also shown (only in KCl-contracted arteries). ${ }^{*} P<0.05$ vs control for difference in $E_{\max } . \mathbf{b}, \mathbf{c}$ Incubation under chronic hypoxia $\left(15 \% \mathrm{O}_{2}\right.$ from day 0$)$ did not affect hydroxyfasudil-induced relaxation of (b) $\mathrm{KCl}$ - or (c) PE-contracted arteries

affect hydroxyfasudil-induced relaxation of KCl- $\left(E_{\max }\right.$ : 99.01\%, SD 16.05; $\mathrm{pD}_{2}: 6.12$, SD 0.70$)$, or PE-contracted arteries $\left(E_{\max }: 101.20 \%\right.$, SD $\left.10.03 ; \mathrm{pD}_{2}: 6.41, \mathrm{SD} 0.95\right)$. 


\section{Discussion}

$\mathrm{Ca}^{2+}$ sensitization in smooth muscle involves multiple cell signaling strategies, including activation of Rho-kinase and PKC. In the present study, we found that treatment with the selective inhibitor of Rho-kinase hydroxyfasudil completely relaxed chicken embryo femoral artery rings contracted with $\mathrm{KCl}$ or PE. Also the contractions induced by the thromboxane $\mathrm{A}_{2}$ mimetic U46619 and ET-1 were reduced in the presence of hydroxyfasudil. Our findings are indicative of a role for Rho-kinase activity in depolarization- and agonist-induced force generation in chicken embryo femoral arteries. In contrast, inhibition of PKC by chelerythrine did not affect $\mathrm{KCl}$ - or PE-induced contractions, indicating a lack of participation of PKC-mediated $\mathrm{Ca}^{2+}$ sensitization.

Chicken embryo femoral artery contraction elicited by $\mathrm{KCl}$ comprises two phases (phasic and tonic contraction), both of which are dependent on influx of extracellular $\mathrm{Ca}^{2+}$. In contrast, Rho-kinase inhibition left the initial phasic component nearly intact but abolished the tonic component. $\mathrm{KCl}$-induced contraction has long been known to be due to membrane depolarization causing $\mathrm{Ca}^{2+}$ entry through voltage-operated $\mathrm{Ca}^{2+}$ channels, activation of $\mathrm{Ca}^{2+}$-dependent MLCK, and increase in MLC phosphorylation (Ratz et al. 2005). However, in the past few years numerous experimental evidences indicate that, by increasing intracellular $\mathrm{Ca}^{2+}$ concentration, $\mathrm{KCl}$ has the potential to act as a stimulus to change the degree of $\mathrm{Ca}^{2+}$ sensitivity in mammalian vessels (Buyukafsar et al. 2006; Kupittayanant et al. 2001; Mita et al. 2002; Ratz et al. 2005; Sakamoto et al. 2003; Sakurada et al. 2003). The mechanisms by which high extracellular $\mathrm{K}^{+}$induces $\mathrm{Ca}^{2+}$ sensitization is not yet fully understood but appears to involve translocation and activation of Rho-kinase (Ratz et al. 2005). In fact, Rho-kinase inhibitors such as Y-27632, fasudil, or hydroxyfasudil inhibited $\mathrm{KCl}$-induced contraction of most smooth muscle types in many mammalian species, including human (Buyukafsar et al. 2006; Kupittayanant et al. 2001), rat (Mita et al. 2002; Sakamoto et al. 2003), rabbit (Sakurada et al. 2003), mouse (Ayman et al. 2003), pig (Janssen et al. 2004), cow (Janssen et al. 2004), and sheep (Levent and Buyukafsar 2004). Our present results suggest that $\mathrm{KCl}$-evoked contraction also involves Rho-kinase-mediated $\mathrm{Ca}^{2+}$ sensitization in chicken embryo vascular smooth muscle.

As mentioned above, the published information about the effects of Rho-kinase inhibition on vascular smooth muscle reactivity in non-mammalian species is scarce. In the chicken embryo ductus arteriosus, hydroxyfasudil and $\mathrm{Y}-27632$ impaired the contractions induced by $\mathrm{KCl}$, oxygen, 4-aminopyridine, PE, and ET-1 (Cogolludo et al. 2009; Greyner and Dzialowski 2008; Van der Sterren et al. 2009; Villamor et al. 2008). Interestingly, the first smooth muscle in which Rho-kinase was isolated and characterized was the chicken gizzard (Feng et al. 1999b). Chicken gizzard has been widely used as a source of smooth muscle contractile proteins for biochemical study and its smooth muscle is classified as a typical phasic-type muscle because it shows only a transient contraction with no sustained phase in response to $\mathrm{KCl}$ or G-protein coupled receptor agonists (Anabuki et al. 2000). Anabuki et al. (2000) observed that chicken gizzard phasic contraction was not affected by the presence of the Rho-kinase inhibitor Y27632. Moreover, when $\mathrm{Ca}^{2+}$ sensitization was tested through the effect of stimulation of small G-proteins by the unhydrolyzable analog of GTP GTP $\gamma \mathrm{S}$, it was found that the degree of $\mathrm{Ca}^{2+}$ sensitization was less in chicken gizzard than in chicken cranial tibial artery. This suggests that Rhokinase-induced $\mathrm{Ca}^{2+}$ sensitization might be of a lesser relevance in the phasic-type gizzard smooth muscle than in the tonic-type vascular smooth muscle (Anabuki et al. 2000).

In smooth muscle cells, Rho-kinase increases MLC phosphorylation through inhibiting MLCP activity, which leads to contraction. The specific mechanism responsible for MLCP inhibition appears to be species, tissue, and agonist dependent (El-Toukhy et al. 2006). MLCP is a trimeric protein consisting of three subunits: a myosin-binding subunit (MYPT1), a catalytic subunit (PP1c $\delta$ ), and a $20-\mathrm{kDa}$ subunit of an unknown function. Two mechanisms for MLCP inhibition are widely accepted: (1) the phosphorylation of MYPT1, and (2) the binding of phosphatase inhibitor proteins, such as CPI-17 or the phosphoprotein holoenzyme inhibitor-1 (PHI-1), to the catalytic subunit of the enzyme (El-Toukhy et al. 2006; Ratz et al. 2005; Somlyo and Somlyo 2003; Webb 2003). Rho-kinase has been demonstrated to phosphorylate MYPT1 at Thr695 in the avian (Feng et al. 1999a), or Thr697 in the mammalian sequence (Somlyo and Somlyo 2003). However, El-Toukhy et al. (2005) demonstrated that phosphorylation of MYPT1 does not participate in $\mathrm{Ca}^{2+}$ sensitization of chicken smooth muscle tissue. An alternative mechanism for $\mathrm{Ca}^{2+}$ sensitization would be a Rho-kinase or PKC-mediated phosphorylation of CPI-17. However, CPI-17 was undetectable in chicken smooth muscle (aorta, mesenteric artery, gizzard, and small intestine) (Kitazawa et al. 2004). This raises the possibility that another phosphatase inhibitor protein mediates $\mathrm{Ca}^{2+}$ sensitization in chicken smooth muscle. Accordingly, El-Toukhy et al. (2006) demonstrated that in chicken gizzard smooth muscle a Rho-kinase-mediated pathway induced an increase in PHI-1 phosphorylation and contractile force.

The absence of CPI-17 in chicken smooth muscles presented a useful model system for studying the role of phosphatase inhibitor proteins in $\mathrm{Ca}^{2+}$ sensitization. In the study of Kitazawa et al., the absence of CPI-17 in adult chicken aorta and mesenteric arteries correlated with a lack 
of PKC-dependent $\mathrm{Ca}^{2+}$ sensitization (Kitazawa et al. 2004). Moreover, they observed that PDBu-mediated PKC activation did not evoke significant contraction in either intact or permeabilized adult chicken mesenteric arteries (Kitazawa et al. 2004). In contrast, we observed that in chicken embryo femoral arteries PDBu induced a significant contraction, which was completely dependent on influx of extracellular $\mathrm{Ca}^{2+}$ and partially inhibited in the presence of hydroxyfasudil. However, neither $\mathrm{KCl}$ - nor $\mathrm{PE}$-induced contraction were affected by the PKC inhibitor chelerythrine. Our data, therefore, suggest that PKC activation does not mediate the contractile responses induced by $\mathrm{KCl}$ or $\mathrm{PE}$ in chicken embryo femoral arteries but also that direct PKC activation is capable of developing a contraction in these vessels. $\mathrm{Ca}^{2+}$ sensitization is not the only pathway by which PKC induces contraction and other signaling proteins implicated, such as mitogen-activated protein kinases (MAPKs), are expressed in chicken smooth muscles (Kitazawa et al. 2004). Developmental changes in the signaling pathways that mediate PKC-induced contraction have been described in mammalian vessels. In ovine cerebral arteries, $\mathrm{PDBu}$ induced $\mathrm{Ca}^{2+}$-dependent contraction in fetal animals and $\mathrm{Ca}^{2+}$-independent contraction in the adult (Longo et al. 2000). This suggests that in fetal cerebral arteries, PKC-induced contraction is more coupled to $\mathrm{Ca}^{2+}$ flux than to $\mathrm{Ca}^{2+}$ sensitivity mechanisms. Whether these developmental changes are also present in chicken vessels warrants further investigation.

Besides its profound effects on smooth muscle cells, Rho-kinase is also involved in the regulation of endothelial NO synthase (eNOS) in mammalian vessels (Bussemaker et al. 2007; Ming et al. 2002). Rho-kinase can directly inhibit eNOS (Sugimoto et al. 2007) and incubation of human endothelial cells with hydroxyfasudil resulted in increased NO production (Wolfrum et al. 2004). Furthermore, inhibition of Rho-kinase by hydroxyfasudil and Y27632, or by overexpression of a dominant-negative mutant of Rho-kinase, increases eNOS mRNA half-life and expression (Rikitake et al. 2005). In chicken embryo femoral arteries we observed that the blockade of NOS with L-NAME produced a slight but significant attenuation of hydroxyfasudil-induced relaxation. This suggests that in chicken embryo femoral arteries a very small portion of the relaxation induced by Rho-kinase inhibition is mediated by $\mathrm{NO}$ and that vascular bioavailable NO might be partly regulated by Rho-kinase.

Numerous studies have shown that chronic hypoxia decreases the growth of developing chicken embryos (Been et al. 2009; Dzialowski et al. 2002; Giussani et al. 2007; Ruijtenbeek et al. 2003b; Villamor et al. 2004; Zoer et al. 2009) and induces a broad spectrum of structural and functional vascular alterations (Ruijtenbeek et al. 2000, 2003a, b; Van der Sterren et al. 2009; Villamor et al. 2004). As reported elsewhere, chronic moderate hypoxia in the chicken embryo led, in the femoral artery, to impairment of endothelium-dependent relaxation (Ruijtenbeek et al. 2003b; Villamor et al. 2004) and increased periarterial sympathetic innervation (Ruijtenbeek et al. 2000) Experimental evidences indicate that chronic hypoxia augments Rho-kinase-induced vascular smooth muscle $\mathrm{Ca}^{2+}$ sensitization in mammalian vessels (Bailly et al. 2004; Jernigan et al. 2004; McNamara et al. 2008; Oka et al. 2007). In the present study, we observed that hypoxia-induced growth retardation was not accompanied by significant changes in the potency or efficacy of hydroxyfasudil to relax chicken embryo femoral arteries. Previously, we demonstrated that the relaxation evoked by Y-27632 and hydroxyfasudil was similar in the ductus arteriosus from normoxic and hypoxic chicken embryos (Van der Sterren et al. 2009). These data indirectly suggest that Rho-kinase activity in the chicken embryo vasculature is unaffected by chronic prenatal hypoxia.

Approximately $1 \%$ of the human genome encodes proteins that either regulate or are regulated by direct interaction with members of the Rho family of small GTPases. Through a series of complex biochemical networks, these highly conserved molecular switches control some of the most fundamental processes of cell biology (Jaffe and Hall 2005). Our present results provide the first functional evidence for a role of the Rho-kinase pathway of $\mathrm{Ca}^{2+}$ sensitization in depolarization- and agonist-mediated contraction of chicken embryo arteries. They warrant further investigation through simultaneous measurement of intracellular $\mathrm{Ca}^{2+}$ and contractile force, as well as determination of developmental changes on the expression of key proteins involved in $\mathrm{Ca}^{2+}$ sensitization.

Acknowledgment This work was supported by a grant of "Stichting Sint Annadal".

Open Access This article is distributed under the terms of the Creative Commons Attribution Noncommercial License which permits any noncommercial use, distribution, and reproduction in any medium, provided the original author(s) and source are credited.

\section{References}

Agren P, van der Sterren S, Cogolludo AL, Frazziano G, de Mey JG, Blanco CE, Villamor E (2008) Developmental changes in endothelium-dependent relaxation of the chicken ductus arteriosus. J Physiol Pharmacol 59:55-76

Agren P, van der Sterren S, Cogolludo AL, Blanco CE, Villamor E (2009) Developmental changes in the effects of prostaglandin E2 in the chicken ductus arteriosus. J Comp Physiol B 179:133-143

Anabuki J, Hori M, Hayakawa K, Akahane S, Ozaki H, Karaki H (2000) Muscarinic stimulation does not induce rhoA/ROCKmediated $\mathrm{Ca}^{2+}$ sensitization of the contractile element in chicken gizzard smooth muscle. Pflugers Arch 441:189-199 
Ayman S, Wallace P, Wayman CP, Gibson A, McFadzean I (2003) Receptor-independent activation of Rho-kinase-mediated calcium sensitisation in smooth muscle. Br J Pharmacol 139:15321538

Bailly K, Ridley AJ, Hall SM, Haworth SG (2004) RhoA activation by hypoxia in pulmonary arterial smooth muscle cells is age and site specific. Circ Res 94:1383-1391

Been JV, Zoer B, Kloosterboer N, Kessels CG, Zimmermann LJ, van Iwaarden JF, Villamor E (2009) Pulmonary vascular endothelial growth factor expression and disaturated phospholipid content in a chicken model of hypoxia-induced fetal growth restriction. Neonatology 97:183-189

Breitenlechner C, Gassel M, Hidaka H, Kinzel V, Huber R, Engh RA, Bossemeyer D (2003) Protein kinase A in complex with Rho-kinase inhibitors Y-27632, Fasudil, and H-1152P: structural basis of selectivity. Structure 11:1595-1607

Bussemaker E, Pistrosch F, Forster S, Herbrig K, Gross P, Passauer J, Brandes RP (2007) Rho kinase contributes to basal vascular tone in humans: role of endothelium-derived nitric oxide. Am J Physiol Heart Circ Physiol 293:H541-H547

Buyukafsar K, Akca T, Nalan Tiftik R, Sahan-Firat S, Aydin S (2006) Contribution of Rho-kinase in human gallbladder contractions. Eur J Pharmacol 540:162-167

Cogolludo A, Moreno L, Villamor E (2007) Mechanisms controlling vascular tone in pulmonary arterial hypertension: implications for vasodilator therapy. Pharmacology 79:65-75

Cogolludo AL, Moral-Sanz J, van der Sterren S, Frazziano G, van Cleef AN, Menéndez C, Zoer B, Moreno E, Roman A, PérezVizcaino F, Villamor E (2009) Maturation of $\mathrm{O}_{2}$ sensing and signaling in the chicken ductus arteriosus. Am J Physiol Lung Cell Mol Physiol 297:L619-L630

Davies SP, Reddy H, Caivano M, Cohen P (2000) Specificity and mechanism of action of some commonly used protein kinase inhibitors. Biochem J 351:95-105

Dzialowski EM, von Plettenberg D, Elmonoufy NA, Burggren WW (2002) Chronic hypoxia alters the physiological and morphological trajectories of developing chicken embryos. Comp Biochem Physiol 131:713-724

El-Toukhy A, Given AM, Cochard A, Brozovich FV (2005) PHI-1 induced enhancement of myosin phosphorylation in chicken smooth muscle. FEBS Lett 579:4271-4277

El-Toukhy A, Given AM, Ogut O, Brozovich FV (2006) PHI-1 interacts with the catalytic subunit of myosin light chain phosphatase to produce a $\mathrm{Ca}^{2+}$ independent increase in MLC20 phosphorylation and force in avian smooth muscle. FEBS Lett 580:5779-5784

Feng J, Ito M, Ichikawa K, Isaka N, Nishikawa M, Hartshorne DJ, Nakano T (1999a) Inhibitory phosphorylation site for Rho-associated kinase on smooth muscle myosin phosphatase. J Biol Chem 274:37385-37390

Feng J, Ito M, Kureishi Y, Ichikawa K, Amano M, Isaka N, Okawa K, Iwamatsu A, Kaibuchi K, Hartshorne DJ, Nakano T (1999b) Rhoassociated kinase of chicken gizzard smooth muscle. J Biol Chem 274:3744-3752

Gao Y, Portugal AD, Negash S, Zhou W, Longo LD, Usha Raj J (2007) Role of Rho kinases in PKG-mediated relaxation of pulmonary arteries of fetal lambs exposed to chronic high altitude hypoxia. Am J Physiol Lung Cell Mol Physiol 292:L678-L684

Giussani DA, Salinas CE, Villena M, Blanco CE (2007) The role of oxygen in prenatal growth: studies in the chick embryo. J Physiol 585:911-917

Greyner H, Dzialowski EM (2008) Mechanisms mediating the oxygen-induced vasoreactivity of the ductus arteriosus in the chicken embryo. Am J Physiol Regul Integr Comp Physiol 295:R1647R1659

Jaffe AB, Hall A (2005) Rho GTPases: biochemistry and biology. Annu Rev Cell Dev Biol 21:247-269
Janssen LJ, Tazzeo T, Zuo J, Pertens E, Keshavjee S (2004) KCl evokes contraction of airway smooth muscle via activation of RhoA and Rho-kinase. Am J Physiol Lung Cell Mol Physiol 287:L852-L858

Jernigan NL, Walker BR, Resta TC (2004) Chronic hypoxia augments protein kinase $\mathrm{G}$-mediated $\mathrm{Ca}^{2+}$ desensitization in pulmonary vascular smooth muscle through inhibition of RhoA/Rho kinase signaling. Am J Physiol Lung Cell Mol Physiol 287:L1220-L1229

Kitazawa T, Eto M, Woodsome TP, Khalequzzaman M (2003) Phosphorylation of the myosin phosphatase targeting subunit and CPI17 during $\mathrm{Ca}^{2+}$ sensitization in rabbit smooth muscle. J Physiol 546:879-889

Kitazawa T, Polzin AN, Eto M (2004) CPI-17-deficient smooth muscle of chicken. J Physiol 557:515-528

Kupittayanant S, Burdyga T, Wray S (2001) The effects of inhibiting Rho-associated kinase with Y-27632 on force and intracellular calcium in human myometrium. Pflugers Arch 443:112-114

Levent A, Buyukafsar K (2004) Expression of Rho-kinase (ROCK-1 and ROCK-2) and its substantial role in the contractile activity of the sheep ureter. Br J Pharmacol 143:431-437

Longo LD, Zhao Y, Long W, Miguel C, Windemuth RS, Cantwell AM, Nanyonga AT, Saito T, Zhang L (2000) Dual role of PKC in modulating pharmacomechanical coupling in fetal and adult cerebral arteries. Am J Physiol Regul Integr Comp Physiol 279:R1419-R1429

McNamara PJ, Murthy P, Kantores C, Teixeira L, Engelberts D, van Vliet T, Kavanagh BP, Jankov RP (2008) Acute vasodilator effects of Rho-kinase inhibitors in neonatal rats with pulmonary hypertension unresponsive to nitric oxide. Am J Physiol Lung Cell Mol Physiol 294:L205-L213

Ming XF, Viswambharan H, Barandier C, Ruffieux J, Kaibuchi K, Rusconi S, Yang Z (2002) Rho GTPase/Rho kinase negatively regulates endothelial nitric oxide synthase phosphorylation through the inhibition of protein kinase B/Akt in human endothelial cells. Mol Cell Biol 22:8467-8477

Mita M, Yanagihara H, Hishinuma S, Saito M, Walsh MP (2002) Membrane depolarization-induced contraction of rat caudal arterial smooth muscle involves Rho-associated kinase. Biochem J 364:431-440

Noma K, Oyama N, Liao JK (2006) Physiological role of ROCKs in the cardiovascular system. Am J Physiol Cell Physiol 290:C661-C668

Oka M, Homma N, Taraseviciene-Stewart L, Morris KG, Kraskauskas D, Burns N, Voelkel NF, McMurtry IF (2007) Rho kinase-mediated vasoconstriction is important in severe occlusive pulmonary arterial hypertension in rats. Circ Res 100:923-929

Ratz PH, Berg KM, Urban NH, Miner AS (2005) Regulation of smooth muscle calcium sensitivity: $\mathrm{KCl}$ as a calcium-sensitizing stimulus. Am J Physiol Cell Physiol 288:C769-C783

Riento K, Ridley AJ (2003) Rocks: multifunctional kinases in cell behaviour. Nat Rev Mol Cell Biol 4:446-456

Rikitake Y, Kim HH, Huang Z, Seto M, Yano K, Asano T, Moskowitz MA, Liao JK (2005) Inhibition of Rho kinase (ROCK) leads to increased cerebral blood flow and stroke protection. Stroke 36:2251-2257

Ruijtenbeek K, le Noble FA, Janssen GM, Kessels CG, Fazzi GE, Blanco CE, De Mey JG (2000) Chronic hypoxia stimulates periarterial sympathetic nerve development in chicken embryo. Circulation 102:2892-2897

Ruijtenbeek K, De Mey JG, Blanco CE (2002) The chicken embryo in developmental physiology of the cardiovascular system: a traditional model with new possibilities. Am J Physiol Regul Integr Comp Physiol 283:R549-R550

Ruijtenbeek K, Kessels CG, Janssen BJ, Bitsch NJ, Fazzi GE, Janssen GM, De Mey J, Blanco CE (2003a) Chronic moderate hypoxia during in ovo development alters arterial reactivity in chickens. Pflugers Arch 447:158-167 
Ruijtenbeek K, Kessels LC, De Mey JG, Blanco CE (2003b) Chronic moderate hypoxia and protein malnutrition both induce growth retardation, but have distinct effects on arterial endothelium-dependent reactivity in the chicken embryo. Pediatr Res 53:573-579

Sakamoto K, Hori M, Izumi M, Oka T, Kohama K, Ozaki H, Karaki H (2003) Inhibition of high K+-induced contraction by the ROCKs inhibitor Y-27632 in vascular smooth muscle: possible involvement of ROCKs in a signal transduction pathway. J Pharmacol Sci 92:56-69

Sakurada S, Takuwa N, Sugimoto N, Wang Y, Seto M, Sasaki Y, Takuwa Y (2003) $\mathrm{Ca}^{2+}$-dependent activation of Rho and Rho kinase in membrane depolarization-induced and receptor stimulation-induced vascular smooth muscle contraction. Circ Res 93:548-556

Shimokawa H, Rashid M (2007) Development of Rho-kinase inhibitors for cardiovascular medicine. Trends Pharmacol Sci 28:296-302

Shimokawa H, Seto M, Katsumata N, Amano M, Kozai T, Yamawaki T, Kuwata K, Kandabashi T, Egashira K, Ikegaki I, Asano T, Kaibuchi K, Takeshita A (1999) Rho-kinase-mediated pathway induces enhanced myosin light chain phosphorylations in a swine model of coronary artery spasm. Cardiovasc Res 43:1029-1039

Somlyo AP, Somlyo AV (2003) $\mathrm{Ca}^{2+}$ sensitivity of smooth muscle and nonmuscle myosin II: modulated by $\mathrm{G}$ proteins, kinases, and myosin phosphatase. Physiol Rev 83:1325-1358

Sugimoto M, Nakayama M, Goto TM, Amano M, Komori K, Kaibuchi K (2007) Rho-kinase phosphorylates eNOS at threonine 495 in endothelial cells. Biochem Biophys Res Commun 361:462-467

Van der Sterren S, Agren P, Zoer B, Kessels L, Blanco CE, Villamor E (2009) Morphological and functional alterations of the ductus arteriosus in a chicken model of hypoxia-induced fetal growth retardation. Pediatr Res 65:279-284

Villamor E, Ruijtenbeek K, Pulgar V, De Mey JG, Blanco CE (2002) Vascular reactivity in intrapulmonary arteries of chicken embryos during transition to ex ovo life. Am J Physiol Regul Integr Comp Physiol 282:R917-R927

Villamor E, Kessels C, Ruijtenbeek K, van Suylen R, Belik J, de Mey J, Blanco C (2004) Chronic in ovo hypoxia decreases pulmonary arterial contractile reactivity and induces biventricular cardiac enlargement in the chicken embryo. Am J Physiol Regul Integr Comp Physiol 287:R642-R651

Villamor E, van der Sterren S, Agren P, Zoer B, Blanco CE, Cogolludo AL, Perez-Vizcaino F (2008) Rho kinase inhibitors impair the response of chicken ductus arteriosus to oxygen and other vasoconstrictors. FASEB J 22:1239.21

Wardle RL, Gu M, Ishida Y, Paul RJ (2007) Rho kinase is an effector underlying $\mathrm{Ca}^{2+}$-desensitizing hypoxic relaxation in porcine coronary artery. Am J Physiol Heart Circ Physiol 293:H23-H29

Webb RC (2003) Smooth muscle contraction and relaxation. Adv Physiol Educ 27:201-206

Wolfrum S, Dendorfer A, Rikitake Y, Stalker TJ, Gong Y, Scalia R, Dominiak P, Liao JK (2004) Inhibition of Rho-kinase leads to rapid activation of phosphatidylinositol 3-kinase/protein kinase Akt and cardiovascular protection. Arterioscler Thromb Vasc Biol 24:1842-1847

Zoer B, Kessels L, Vereijken A, De Mey JG, Bruggeman V, Decuypere E, Blanco CE, Villamor E (2009) Effects of prenatal hypoxia on pulmonary vascular reactivity in chickens prone to pulmonary hypertension. J Physiol Pharmacol 60:119-130 